Н. Г. Кучук ${ }^{1}$, Н. В. Лукова-Чуйко ${ }^{2}$, В. В. Собчук ${ }^{3}$

${ }^{1}$ Національний технічний університет «Харківський політехнічний інститут», Харків, Україна

${ }^{2}$ Київський національний університет імені Тараса Шевченка, Київ, Україна

${ }^{3}$ Східноєвропейський національний університет імені Лесі Українки, Луцьк, Україна

\title{
ОПТИМІЗАЦІЯ ПРОПУСКНИХ ЗДАТНОСТЕЙ КАНАЛІВ ЗВ'ЯЗКУ ГІПЕРКОНВЕРГЕНТНОЇ СИСТЕМИ
}

\begin{abstract}
Завдання оптимізації пропускних здатностей каналів зв'язку гіперконвергентної системи потребує застосування сучасних математичних і комп'ютерних методів та засобів. Предметом дослідження $є$ ресурси для передачі даних у гіперконвергентній системі. Мета дослідження - отримання аналітичного рішення задачі оптимізації пропускних здатностей каналів зв'язку гіперконвергентної системи при обмежених вузлових ресурсах. Результати та висновки. Для вирішення завдання оптимізації пропускних здатностей каналів зв'язку гіперконвергентної системи в якості функціоналу оптимізації був обраний середній час затримки при обмеженнях на вартість оренди каналів зв'язку. Оптимізаційна задача сформульована таким чином: визначити оптимальні значення щільності інформаційного потоку, що мінімізують середню затримку при обмеженні на вартість передачі сумарної кількості інформації, що припадає на одиницю пропускної здатності ліній зв'язку. Для її вирішення застосований метод невизначених множників Лагранжа. В результаті отримані аналітичні вирази, які дозволяють при заданій вартості передачі одиниці інформації здійснити вибір кількості елементів буферної пам'яті і оптимального значення щільності потоку інформації, що забезпечує мінімальну середню затримку передачі транзакцій гіперконвергентної комп'ютерної системи.
\end{abstract}

Кл юч ов і с л ов а : канал зв'язку, гіперконвергентна система, пропускна здатність, інформаційний потік.

\section{Ветуп}

Аналіз проблеми та наукових публікацій. На сьогодні на ринку ІТ-технологій розподілені хмарні платформи поступово витісняються конвергентними і гіперконвергентними [1, 2]. Інфраструктура, що створена на конвергентної платформі, передбачає об'єднання пам'яті, обчислювальних і мережних ресурсів в пул, заздалегідь сконфігурованих для роботи в дата-центрі [3], при гіперконвергентній інфраструктурі обчислювальні потужності, сховища, сервери, мережі об'єднуються в одне ціле за допомогою програмних засобів, а управління ними відбувається через загальну консоль адміністрування $[4,5]$. При гіперконвергентній структурі для управління системою часом досить одного системного адміністратора. Це істотно знижує витрати на обслуговування системи. Але виникає питання щодо необхідної кількості та визначенню пропускної здатності каналів зв'язку з дата-центром та центром керування [6].

Численні публікації [7-28], присвячені оптимізації пропускних здатностей мереж передачі даних, базуються на моделі мережі у вигляді системи масового обслуговування типу $\mathbf{M} / \mathbf{M} / \mathbf{1}$ із необмеженими чергами. Таке припущення припускає можливість отримання аналітичного рішення, що суттєво спрощує інтерпретацію результатів, але доволі часто не відповідає реальним умовам функціонування мережі. Особливо це помітно при аналізі гіперконвергентних систем [2]. Основною причиною перевантажень мережі $€$ обмеженість канального ресурсу, пов'язаного 3 вартістю оренди каналів, і кінцевої кількості буферів у вузлах комутації. Аналіз показує, що класична постановка задачі дає завищені значення середнього часу затримки, а обмеження вузлових ресурсів при інших рівних умовах дозволяє транспортувати по мережі більш значні потоки інформації [9]. Однак спроба вирішити це завдання для обмеженої кількості місць у черзі, не дає точного аналітичного рішення через складність функціонала оптимізації [10].

Постановка завдання. Метою статті є отримання аналітичного рішення задачі оптимізації пропускних здатностей каналів зв'язку гіперконвергентної системи при обмежених вузлових ресурсах.

\section{1. Результати теоретичних досліджень}

В якості функціоналу оптимізації будемо використовувати середній час затримки $T_{\text {cep }}$ при обмеженні на вартість оренди каналів зв'язку

$$
C \leq C_{\max } .
$$

Для розрахунку середнього часу затримки $T_{c e p}$ використаємося формулою Літтла [11]

$$
\gamma T_{\text {cep }}=\sum_{i=1}^{n} \lambda_{i} \cdot T_{i},
$$

де $\gamma$ - загальний трафік в мережі; $\lambda_{i}$ - інтенсивність потоку пакетів на вході в кожен канал; $T_{i}-$ середній час затримки пакета в кожній окремій лінії.

Доведено [12], що черги пакетів на вході в кожний канал зв'язку можна апроксимувати системами масового обслуговування типу М/M/1, тобто на вхід $i$-ої черги надходить пуассонівський потік пакетів $з$ інтенсивністю $\lambda_{i}$ пакетів в секунду і середнім часом обслуговування $\mu_{i}^{-1} \mathrm{c}$, який розподілений за експоненціальним законом.

Середній час затримки $T_{i}$, котрий дорівнює часу перебування заявки в системі масового обслуговування (СМО), виражається такою формулою [13]:

$$
T_{i}=\overline{r_{i}} / \lambda_{i}+g_{i} / \mu_{i}
$$




$$
\text { де } \quad g_{i}=\frac{1-\rho_{i}^{m_{i}+1}}{1-\rho_{i}^{m_{i}+2}}-
$$

середня частка заявок, що надійшли, яку обслуговує система (відносна пропускна здатність);

$$
\overline{r_{i}}=\frac{\rho_{i}^{2}\left[1-\rho_{i}^{m_{i}}\left(m_{i}+1-m_{i} \cdot \rho_{i}\right)\right]}{\left(1-\rho_{i}^{m_{i}+2}\right)\left(1-\rho_{i}\right)}-
$$

середня кількість заявок в черзі; $m_{i}$ - кількість місць в черзі;

$$
\rho_{i}=\lambda_{i} / \mu_{i}-
$$

коефіцієнт використання системи.

С урахуванням (4) і (5) вираз (3) після перетворення приймає вигляд:

$$
T_{i}=\frac{1}{\mu_{i}} \frac{1-\rho_{i}^{m_{i}+1}\left[\left(m_{i}+2\right)-\rho_{i}\left(m_{i}+1\right)\right]}{\left(1-\rho_{i}^{m_{i}+1}\right)\left(1-\rho_{i}\right)} .
$$

Однак вираз (6) не зручний для використання в задачі оптимізації через громіздкість. Використовуючи формулу для кінцевої суми геометричної прогресії

$$
\sum_{k=0}^{m_{i}+1} \rho^{k}=\frac{1-\rho^{m_{i}+2}}{1-\rho}=S_{m_{i}}
$$

його легко надати в більш зручній формі:

$$
=\frac{1}{\mu_{i}} \cdot \frac{\sum_{k=0}^{m_{i}}(1+k) \rho_{i}^{k}}{\sum_{k=0}^{m_{i}+1} \rho_{i}^{k}}=\frac{1}{\mu_{i}} \cdot \frac{\left(\sum_{k=0}^{m_{i}+1} \rho_{i}^{k}\right)^{\prime}}{\sum_{k=0}^{m_{i}+1} \rho_{i}^{k}}=\frac{1}{\mu_{i}} \frac{S_{m_{i}}^{\prime}}{S_{m_{i}}}
$$

де штрих - це похідна $\frac{\partial}{\partial \rho}$.

Тому середній час затримки у всій мережі знаходиться $з$ (1) з урахуванням (6):

$$
T_{c p}=\frac{1}{\gamma} \sum_{i=1}^{n} \rho_{i} \frac{\left(\sum_{k=0}^{m_{i}+1} \rho_{i}^{k}\right)^{\prime}}{\sum_{k=0}^{m_{i}+1} \rho_{i}^{k}}=\frac{1}{\gamma} \sum_{i=1}^{n} \rho_{i} \frac{S_{m_{i}}^{\prime}}{S_{m_{i}}} .
$$

Залежність (7) при $m_{i} \rightarrow \infty$ переходить у відому формулу

$$
T_{c p}=\frac{1}{\gamma} \sum_{i=1}^{n} \frac{\rho_{i}}{1-\rho_{i}}
$$

з необмеженою чергою [14], а при $m_{i}=0$ :

$$
T_{c p}=\frac{1}{\gamma} \sum_{i=1}^{n} \frac{\rho_{i}}{1+\rho_{i}}
$$

що відповідає моделі мережі у вигляді СМО з відмовами [22].
Дослідження показали, що функція (8) є опуклою функцією, але не містить екстремумів, в зв'язку 3 чим мінімум середнього часу затримки не може бути знайдений шляхом обчислення часткових похідних $\frac{\partial T_{c p}}{\partial \rho_{i}}=0$. У зв'язку з цим дана задача $\epsilon$ задачею умовної оптимізації. Аналітичне рішення поставленого завдання можливо при відповідному виборі в якості обмежує умови функції вартості. Розрахунки [15] показують, що зазвичай немає великої різниці між випадками використання вартісних функцій того чи іншого вигляду, тобто слід вибирати ту вартісну функцію, яка найбільш повно відповідає умовам конкретного завдання [15].

Розглянемо вартісну функцію вигляду [16]:

$$
C=k \sum_{i=1}^{n} \frac{F_{i}}{V_{i}}
$$

де при пакетній передачі повідомлень

$$
F_{i}=L \lambda_{i}, V_{i}=L \mu_{i} ;
$$

$L$ - фіксована довжина пакета у бітах.

3 урахуванням цього функція вартості (9) набирає вигляду

$$
C=k \sum_{i=1}^{n} \rho_{i}
$$

і виражається в одиницях вартості передачі одиниці кількості інформації (тобто щільності інформаційного потоку, що в загальному відповідає прийнятим принципам оплати за використання засобів зв'язку), $\rho_{i}$-коефіцієнт використання каналу або завантаження мережі.

Таким чином, оптимізаційна задача може бути сформульована в такому вигляді:

визначити оптимальні значення щільності інформаційного потоку, щзо мінімізують середню затримку

$$
T_{c p}=\frac{1}{\gamma} \sum_{i=1}^{n} \rho_{i} \frac{S_{m_{i}}^{\prime}}{S_{m_{i}}} \rightarrow \min
$$

при обмеженні на вартість передачі сумарної кількості інформації, щуо припадає на одиницю пропускної здатності ліній зв'язку

$$
C=k \sum_{i=1}^{n} \rho_{i} \leq C_{3 а д} .
$$

Для вирішення даного завдання застосований метод невизначених множників Лагранжа. Складемо функціонал оптимізації:

$$
\Phi=\frac{1}{\gamma} \sum_{i=1}^{n} \rho_{i} \frac{S_{m_{i}}^{\prime}}{S_{m_{i}}}+P k \sum_{i=1}^{n} \rho_{i}
$$

де $P$ - невизначений множник Лагранжа.

Обчислюючи часткові похідні $\frac{\partial \Phi}{\partial \rho_{i}}=0$, отримаємо систему $n$ рівнянь вигляду 


$$
\left(\rho_{i} \frac{S_{m_{i}}^{\prime}}{S_{m_{i}}}\right)^{\prime}+\gamma P k=0, \quad i=\overline{1, n} .
$$

Аналіз виразу (14) показує, що кожне рівняння, цієї системи залежить від змінної $\rho_{i}$ і параметрів $m_{i}, \gamma, P, k$. Якщо покласти $m_{i}=m$ однаковим для всіх вузлів, то ці характеристики не залежать від індексу $i$, тобто в результаті його рішення відносно $\rho_{i}$ отримуємо

$$
\rho_{i}=F(m, \gamma, P, k) .
$$

Це дозволяє зробити висновок, що

$$
\rho_{i}^{\text {onm }}=\rho=\text { const }
$$

тобто оптимальні значення щільності інформаційного потоку однакові для всіх гілок і не залежать від номера гілки зв'язку.

Після диференціювання і деяких перетворень отримаємо для кожної гілки (опускаючи індекс $i$ ) таке диференційне рівняння:

$$
\frac{S_{m}^{\prime}}{S_{m}}+\rho \frac{S_{m}^{\prime \prime}}{S_{m}}-\rho \frac{\left(S_{m}^{\prime}\right)^{2}}{S_{m}^{2}}+\gamma P k=0 .
$$

Шляхом заміни змінної

$$
\frac{S_{m}^{\prime}}{S_{m}}=Z \quad \text { i } \quad S_{m}^{\prime \prime}=Z^{\prime} S_{m}+Z S_{m}^{\prime}
$$

рівняння (15) перетворюється в неоднорідне лінійне рівняння першого порядку:

$$
Z^{\prime}+\frac{1}{\rho} Z=-\frac{1}{\rho} \gamma P k
$$

Загальне рішення рівняння (17) знаходиться методом варіації вільної постійної [22]. Відповідне однорідне рівняння

$$
Z^{\prime}+\frac{1}{\rho} Z=0,
$$

iз роздільними змінними має спільне рішення в такому вигляді:

$$
Z=\frac{C_{1}}{\rho} .
$$

Покладемо $C_{1}=C_{1}(\rho)$, тоді

$$
Z=\frac{C_{1}(\rho)}{\rho} \text {. }
$$

Виберемо функцію $C_{1}(\rho)$ так, щоб вираз (20) задовольняло рівнянням (16). Підставляючи (20) в (17) після перетворень, отримаємо

$$
C_{1}^{\prime}(\rho)=-\gamma P k \text {. }
$$

Інтегруючи (21), маємо

$$
C_{1}(\rho)=-\gamma P k \rho+C_{2}
$$

i, отже,

$$
Z=-\gamma P k+\frac{C_{2}}{\rho} .
$$

Повертаючись до попередньої змінної із (17), отримаємо:

$$
S_{m}^{\prime} / S_{m}=-\gamma P k+\left(C_{2} / \rho\right) .
$$

Розділивши у виразі (23) змінні, прийдемо до такого рівняння

$$
\frac{d S_{m}}{S_{m}}=-\gamma P k d \rho+C_{2} \frac{d \rho}{\rho},
$$

інтегруючи яке, остаточно отримуємо

$$
S_{m}=C_{3} \rho^{c_{2}} \cdot e^{-\gamma P k \rho},
$$

де $C_{2}$ та $C_{3}$ - постійна інтегрування.

За рівняння (24) знаходимо довільні постійні інтегрування $C_{2}$ та $C_{3}$ шляхом розв'язання задачі Коші при заданих початкових умовах.

У подальших розрахунках обмежимося залежністю (23), із якої визначимо значення $\rho$ для кожної гілки розглянутої мережі:

$$
\rho=\frac{C_{2}}{\gamma P k+\left(S_{m}^{\prime} / S_{m}\right)} .
$$

Визначимо значення $C_{2}$ з початкової умови $\rho_{o}=1$. Згідно рівняння (8)

$$
\begin{gathered}
\left(S_{m}^{\prime} / S_{m}\right)_{\rho=1}=\frac{1+2+\cdots+(m+1)}{\underbrace{1+1+\cdots+1}_{m+2}}= \\
=\frac{(m+1)(m+2)}{2(m+2)}=\frac{m+1}{2} .
\end{gathered}
$$

У виразі (26) враховано, що чисельник

$$
1+2+\ldots+\left(m_{i}+1\right)=\frac{(m+1)(m+2)}{2}
$$

є сумою арифметичної прогресії.

3 рівняння (25) за умови (26) визначаємо довільну постійну $C_{2}$ :

$$
C_{2}=\gamma P k+\frac{m+1}{2} .
$$

Остаточно отримуємо:

$$
\rho=\left(\gamma P k+\frac{m+1}{2}\right) /\left(\gamma P k+\left(S_{m}^{\prime} / S_{m}\right)\right) \text {. }
$$

Для визначення невизначеного множника Лагранжа скористаємося умовою (12) для граничного значення вартості:

$$
\begin{aligned}
& k \sum_{i=1}^{n} \frac{\gamma P k+(m+1) / 2}{\gamma P k+\left(S_{m}^{\prime} / S_{m}\right)}= \\
= & k n \frac{\gamma P k+(m+1) / 2}{\gamma P k+\left(S_{m}^{\prime} / S_{m}\right)}=C_{3 а д} .
\end{aligned}
$$


Із отриманого виразу (30) отримуємо значення множника Лагранжу:

$$
P=\frac{(m+1) / 2-\left(S_{m}^{\prime} / S_{m}\right) \cdot\left(C_{\text {зад }} / k n\right)}{\gamma k\left(\left(C_{\text {зад }} / k n\right)-1\right)} .
$$

Підставляючи (31) в (29), отримаємо умови екстремумів $T_{\text {cep }}$ виразу (8):

$$
\left(\rho_{\text {onm }}-\frac{C_{3 a \partial}}{k n}\right)\left((m+1) / 2-S_{m}^{\prime} / S_{m}\right)=0 .
$$

Умови (32) виконуються, якщо будь-який співмножник дорівнює нулю, тобто

$$
\begin{gathered}
\rho_{\text {onm }}-C_{\text {зад }} / k n=0 ; \\
S_{m}^{\prime} / S_{m}-(m+1) / 2=0 .
\end{gathered}
$$

Умова (33) визначає оптимальне значення питомої потоку у гілках:

$$
\rho_{\text {onm }}=C_{\text {зад }} / k n,
$$

що забезпечує мінімальне значення середнього часу затримки:

$$
T_{\text {cep }}^{\min }=\frac{1}{\gamma} \cdot \frac{C_{\text {заd }}}{k} \cdot\left(\frac{S_{m}^{\prime}}{S_{m}}\right)_{\text {onm }}, 0<\rho_{\text {onm }}<1 .
$$

Умова (34) відповідає максимальному значенню затримки в мережі при

$$
\rho=1, T_{c p}^{\max }=\frac{n}{\gamma} \cdot \frac{m+1}{2},
$$

яке досягається незалежно від вартості мережі.

\section{2. Результати експериментальних досліджень}

Аналіз отриманих результатів показує, що вартість мережі визначається в основному витратами на передачу даних, тому необхідно ресурси мережі використовувати максимально ефективно.
Згідно із виразом (34) можна зробити висновок, що мережа зв'язку повинна бути однорідною в сенсі постійності значень щільності потоку інформації, що передається в усіх лініях зв'язку. Виходячи із цього, можна стверджувати, що в такому випадку

$$
\rho_{\text {onm }}=C_{\text {зад }} / k n<1
$$

не залежить від номера гілки зв'язку.

Якщо потоки в гілках при синтезі мережі задані у вигляді матриці тяжінь $\left\|\lambda_{i}\right\|$, то при фіксованій довжині пакета $L$ пропускні здатності відповідних гілок прямо пропорційні значенням потоків цих гілок, тобто

$$
V_{i}=\left(k n / C_{3 а д ~}\right) \cdot F_{i},
$$

що $є$ необхідною умовою винятком блокувань мережі, тобто

$$
V_{i}>F_{i}
$$

причому ступінь цього перевищення визначається відношенням кількості гілок мережі до їх вартості.

Припущення про те, що $m$ не залежить від номера вузла або гілки є приблизно вірним, так як згідно $з$ (39) збільшення потоку $F_{i}$ призводить до необхідності пропорційного збільшення пропускної здатності, що веде до більш швидкого звільнення буферів, так що кількість вимог на вході до кожного каналу залишається незмінною, тобто необхідна кількість буферів виявляється постійною.

Залежності мінімальних значень середньої затримки при всіляких значеннях кількості буферів у вузлах комутації від оптимальних значень питомого потоку представлені на рис. 1.

Припущення про нескінченну кількість буферів дозволяє отримати верхнє значення для затримки, яку можна досягти при кінцевому числі елементів буферної пам'яті, при цьому затримка в системі без буферів дає нижнє значення для затримки у системах множинного доступу з буферизацією та керуємим потоком.

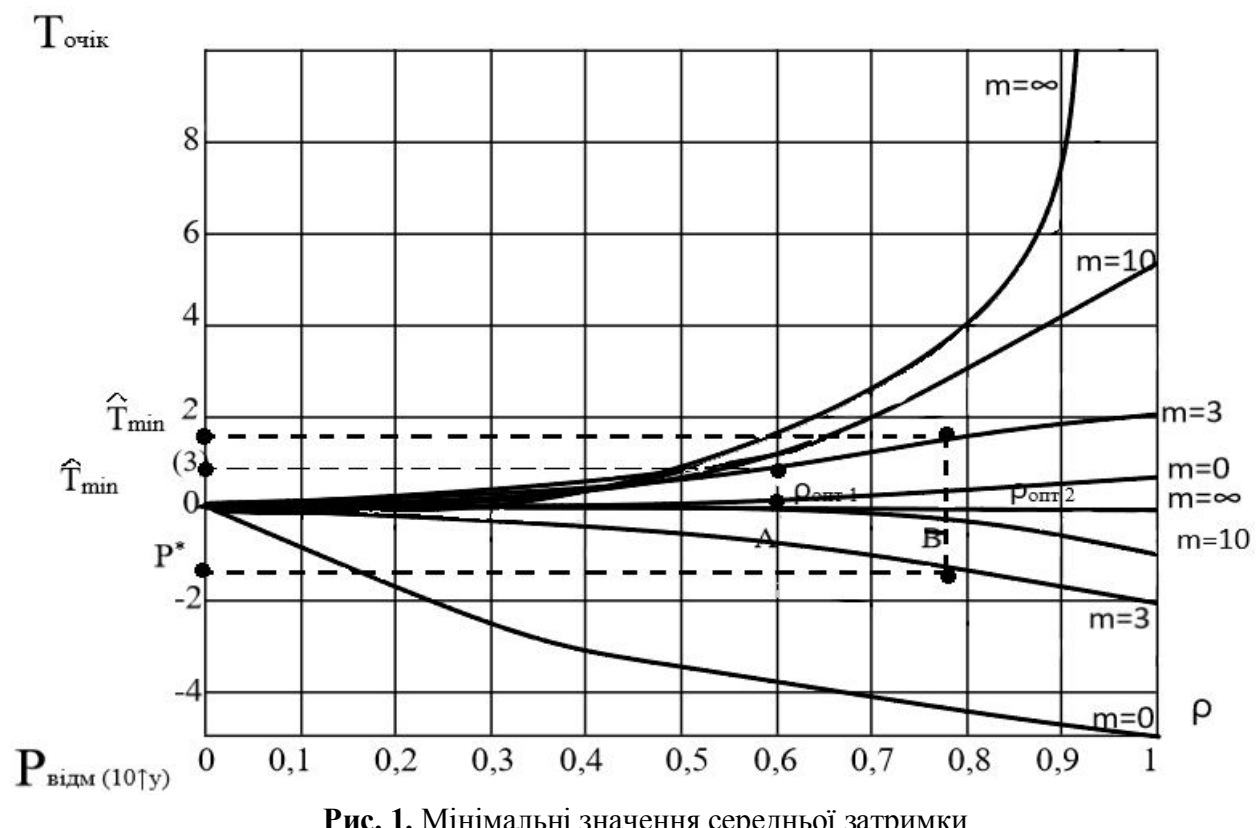

Рис. 1. Мінімальні значення середньої затримки 
Однак обмеження на кількість буферів у вузлах комутації неминуче призводить до того, що частина пакетів відкидається вузлом.

Для врахування цієї обставини на рис. 1, наведені суміщені криві залежності ймовірності відмов у функції $f(\rho)$ при однакових значеннях кількості буферів $m$, побудовані відповідно до виразу [21]

$$
P_{\text {отк }}(\rho, m)=\frac{\rho^{m+1}}{\sum_{n=0}^{m+1} \rho^{k}} .
$$

Аналіз кривих рис. 1 дозволяє зробити висновок про те, що значення мінімальної середньої затримки $\left(T_{\min }=1,8 \mathrm{c}\right)$, яка відповідає значенням $\rho_{\text {onm }}=0,6 ; m=\infty$ (точка А) може бути досягнуто при більш високій щільності інформаційного потоку $\left(\rho_{\text {олm }}^{\prime \prime}=0,78 ; m=3\right)$ при обмеженій кількості буферів в вузлах комутації (точка В). При цьому ймовірність відмови $P^{*}=0,12$, що приблизно відповідає значенню $\sim 10 \%$ і є цілком прийнятним [22].

\section{Висновок}

Для вирішення завдання оптимізації пропускних здатностей каналів зв'язку гіперконвергентної системи в якості функціоналу оптимізації був обраний середній час затримки при обмеженнях на вартість оренди каналів зв'язку. Оптимізаційна задача сформульована таким чином: визначити оптимальні значення щільності інформаційного потоку, що мінімізують середню затримку при обмеженні на вартість передачі сумарної кількості інформації, що припадає на одиницю пропускної здатності ліній зв'язку. Для іiї вирішення застосований метод невизначених множників Лагранжа.

В результаті отримані аналітичні вирази, які дозволяють при заданій вартості передачі одиниці інформації здійснити вибір кількості елементів буферної пам'яті і оптимального значення щільності потоку інформації, що забезпечує мінімальну середню затримку передачі транзакцій гіперконвергентної комп'ютерної системи.

Напрям подальших досліджень - реалізація запропонованої математичної моделі у гіперконвергентному середовищі.

\section{СПИСОК ЛІТЕРАТУРИ}

1. Шматков С. I. Модель інформаційної структури гіперконвергентної системи підтримки електронних обчислювальних ресурсів університетської е-learning / С. І. Шматков, Н. Г. Кучук, В. В. Донець // Системи управління, навігації та зв'язку : науковий журнал. - Полтава : ПНТУ, 2018. - Вип. 2 (48). - С. 97-100.

2. Merlac V. Resourses Distribution Method of University e-learning on the Hypercovergent platform / V. Merlac, S. Smatkov, N. Kuchuk, A. Nechausov // Conf. Proc. of 2018 IEEE $9^{\text {th }}$ International Conference on Dependable Systems, Service and Technologies. DESSERT'2018. Ukraine, Kyiv, May 24-27, 2018. - P. 136-140. - URL : http://dx.doi.org/ 10.1109/DESSERT.2018.8409114

3. Donets V., Kuchuk N., Shmatkov S. Development of software of e-learning information system synthesis modeling process. Сучасні інформаційні системи. 2018. Т. 2, № 2. C. 117-121. DOI: https://doi.org/10.20998/2522-9052.2018.2.20.

4. Зиков I. С., Кучук Н. Г., Шматков С. І. Синтез архітектури комп'ютерної системи управління транзакціями е-learning. Сучасні інформаційні системи. 2018. Т. 2, № 3. С. 60-66. DOI: https://doi.org/10.20998/2522-9052.2018.3.10.

5. Kuchuk N. Method for calculating of R-learning traffic peakedness / N. Kuchuk; O. Mozhaiev, M. Mozhaiev; H. Kuchuk // 2017 4th International Scientific-Practical Conference Problems of Infocommunications Science and Technology, PIC S and T 2017. - 2017. - P. 359 - 362. URL : http://dx.doi.org/10.1109/INFOCOMMST.2017.8246416.

6. Кучук Г.А. Метод оценки характеристик АТМ-трафика / Г.А. Кучук // Інформаційно-керуючі системи на залізничному транспорті, - 2003. - № 6. - С. 44-48.

7. Кучук Г. А., Можаєв О. О., Воробйов О. В. Метод агрегування фрактального трафіка. Радіоелектронні та комп'ютерні системи. 2006. № 6 (18). С. 181-188.

8. Saravana, Balaji B,, Karthikeyan, N.K. and Raj Kumar, R.S., (2018), "Fuzzy service conceptual ontology system for cloud service recommendation", Computers \& Electrical Engineering, Vol. 69, pp. 435-446.

9. Saravana, Balaji B., Mohamed, Uvaze Ahamed, Eswaran C. and Kannan R., (2019), "Prediction-based Lossless Image Compression", Lecture Notes in Computational Vision and Biomechanics (Springer), Vol. 30, No 1, pp.1749 - 17961, DOI: https://doi.org/10.1007/978-3-030-00665-5 161

10. Кучук Г. А. Фрактальный гауссовский шум в трафиковых трассах / Г.А. Кучук // Системи обробки інформації. 2004. - № 3(31). - С. 91-100.

11. Кучук Г.А. Аналіз та моделі самоподібного трафіка / Г.А. Кучук, О.О. О.В. Можаев, Воробйов // Авиационнокосмическая техника и технология. - 2006. - Вып. 9 (35). - С. 173-180.

12. Amin Salih M., Potrus M.Y._A Method for Compensation of TCP Throughput Degrading During Movement Of Mobile Node. ZANCO Journal of Pure and Applied Sciences. 2015. Vol. 27, No 6. P. 59-68.

13. Gomathi, B, Karthikeyan, N.K. and Saravana, Balaji B., (2018), "Epsilon-Fuzzy Dominance Sort Based Composite Discrete Artificial Bee Colony optimization for Multi-Objective Cloud Task Scheduling Problem", International Journal of Business Intelligence and Data Mining, Vol. 13, Issue 1-3, pp. 247-266, DOI: https://doi.org/10.1504/IJBIDM.2018.088435

14. Dhivakar B., Saravanan S.V., Sivaram M., Krishnan R.A. Statistical Score Calculation of Information Retrieval Systems using Data Fusion Technique”. Computer Science and Engineering. 2012. Vol. 2, Issue 5. pp.43-45.

15. Sivaram, M., Batri, K., Amin Salih, Mohammed and Porkodi V. (2019), "Exploiting the Local Optima in Genetic Algorithm using Tabu Search", Indian Journal of Science and Technology, Volume 12, Issue 1.

16. Kuchuk G., Nechausov S., Kharchenko, V. Two-stage optimization of resource allocation for hybrid cloud data store. International Conference on Information and Digital Technologies. 2015. P. 266-271.

17. Ruban, I. Redistribution of base stations load in mobile communication networks / I. Ruban, H. Kuchuk, A. Kovalenko // Innovative technologies and scientific solutions for industries. - 2017. - No 1 (1) - P. 75-81. 
18. Коваленко А.А. Сучасний стан та тенденції розвитку комп'ютерних систем об'єктів критичного застосування / А.А. Коваленко, Г.А. Кучук // Системи управління, навігації та зв’язку. - Полтава . ПНТУ, 2018. - Вип. 1(47). C. 110-113. DOI : https://doi.org/10.26906/SUNZ.2018.1.110

19. Кучук Г. А. Модель процесса эволюции топологической структуры компьютерной сети системы управления объектом критического применения / Г.А. Кучук, А.А. Коваленко, А.А. Янковский // Системи обробки інформації. - 2014. - № 7(123). - С. 93-96.

20. Кучук Г. А. Метод параметрического управления передачей данных для модификации транспортных протоколов беспроводных сетей / Г.А. Кучук, А.С. Мохаммад, А.А. Коваленко // Системи обробки інформації. - 2011. - № 8(98). - С. 211-218.

21. Кучук Г.А. Метод мінімізації середньої затримки пакетів у віртуальних з'єднаннях мережі підтримки хмарного сервісу / Г.А. Кучук, А.А. Коваленко, Н.В. Лукова-Чуйко // Системи управління, навігації та зв’язку. - Полтава . ПНТУ, 2017. - Вип. 2(42). - С. 117-120.

22. Sivaram, M., Yuvaraj, D., Amin Salih, Mohammed, Porkodi, V. and Manikandan V. (2018), "The Real Problem Through a Selection Making an Algorithm that Minimizes the Computational Complexity", International Journal of Engineering and Advanced Technology, Vol. 8, iss. 2, 2018, pp. 95-100.

23. Sivaram, M., Porkodi, V., Mohammed, A.S., Manikandan V. Detection of Accurate Facial Detection Using Hybrid Deep Convolutional Recurrent Neural Network. ICTACT Journal on Soft Computing. 2019. Vol. 09, Issue 02. pp. 1844-1850.

24. Mohammed, A. S. Optimal Forecast Model for Erbil Traffic Road Data. ZANCO Journal of Pure and Applied Sciences. 2017. Vol. 29, No 5. P. 137-145. DOI: https://doi.org/10.21271/ZJPAS.29.5.15

25. Amin Salih M., Yuvaraj D., Sivaram M., Porkodi V. Detection And Removal Of Black Hole Attack In Mobile Ad Hoc Networks Using Grp Protocol. International Journal of Advanced Research in Computer Science. Vol. 9, No 6. P. 1-6.

26. Коваленко А. А., Кучук Г. А. Методи синтезу інформаційної та технічної структур системи управління об'єктом критичного застосування. Сучасні інформаційні системи. 2018. Т. 2, № 1. С. 22-27. DOI: https://doi.org/10.20998/2522-9052.2018.1.04

27. Свиридов А. С., Коваленко А. А., Кучук Г. А. Метод перерозподілу пропускної здатності критичної ділянки мережі на основі удосконалення ON/OFF-моделі трафіку. Сучасні інформачійні системи. 2018. Т. 2, № 2. C. 139-144. DOI: https://doi.org/10.20998/2522-9052.2018.2.24

28. Moiseev A. Investigation of High Intensive General Flow / A. Moiseev, A. Nazarov // Proc. of the IV International Conference «Problems of Cybernetics and Informatics» (PCI'2012), September 12-14, 2012. Baku, Azerbaijan. - Baku: ANAS, 2012. - P. 161-163.

Рецензент: д-р техн. наук, доц. А. А. Коваленко, Харківський національний університет радіоелектроніки, Харків Received (Надійшла) 16.04.2019 Accepted for publication (Прийнята до друку) 29.05.2019

\section{Оптимизация пропускных способностей каналов связи гиперконвергентной системы}

Н. Г. Кучук, Н. В. Лукова-Чуйко, В. В. Собчук

Задача оптимизации пропускных способностей каналов связи гиперконвергентной системы требует применения современных математических и компьютерных методов и средств. Предметом исследования являются ресурсы для передачи данных в гиперконвергентной системе. Цель исследования - получение аналитического решения задачи оптимизации пропускных способностей каналов связи гиперконвергентной системы при ограниченных узловых ресурсах. Результаты и выводы. Для решения задачи оптимизации пропускных способностей каналов связи гиперконвергентной системы в качестве функционала оптимизации было выбрано среднее время задержки при ограничениях на стоимость аренды каналов связи. Оптимизационная задача сформулирована следующим образом: определить оптимальные значения плотности информационного потока, минимизирующие среднюю задержку при ограничении на стоимость передачи суммарного количества информации, приходящейся на единицу пропускной способности линий связи. Для ее решения применен метод неопределенных множителей Лагранжа. В результате получены аналитические выражения, позволяющие при заданной стоимости передачи единицы информации осуществить выбор количества элементов буферной памяти и оптимального значения плотности потока информации, обеспечивает минимальную среднюю задержку передачи транзакций гиперконвергентной компьютерной системы.

Кл юче в ы е сл о в а : канал связи, гиперконвергентная система, пропускная способность, информационный поток.

\section{Optimization of communication channels bandwidths of the hyperconverting system}

N. Kuchuk, N. Lukova-Chuiko, V. Sobchuk

The task of optimizing the bandwidth of hyperconverting communication channels requires the use of modern mathematical and computer methods and tools. The subject of the study is the resources for data transmission in the hyperconverting system. The purpose of the research is to obtain an analytical solution to the task of optimizing the throughput capacities of hyperconverting system communication channels with limited nodal resources. Results and conclusions. In order to solve the problem of optimizing the bandwidth of hyperconverting communication channels as an optimization function, the average delay time was chosen with restrictions on the cost of leased communication channels. The optimization problem is formulated as follows: to determine the optimal values of the density of the information flow, minimizing the average delay in limiting the transmission cost of the total amount of information per unit of bandwidth of the communication lines. To solve it, we use the method of indeterminate Lagrange multipliers. As a result, analytical expressions are obtained, which allow for a given value of transmitting a unit of information to make a choice of the number of buffer memory elements and the optimal value of the information flow density, which ensures a minimal average delay in the transfer of transactions of the hyperconverting computer system.

Keywords : communication channel, hyperconverting system, bandwidth, information flow. 